\title{
Can the Streamliner multilayer flow modulator really streamline the solution to complex arch and thoracoabdominal aortic pathology?
}

\author{
George J. Arnaoutakis, MD, and Wilson Y. Szeto, MD
}

\footnotetext{
From the Division of Cardiovascular Surgery, University of Pennsylvania, Philadelphia, Pa.

Disclosures: W.Y.S. serves as a consultant on an advisory board with Micro Interventional Devices, Inc, and has research grants from Edwards Lifesciences Corporation, Medtronic, Inc, LivaNova, and Bolton Medical. The other author has nothing to disclose with regard to commercial support.

Received for publication June 25, 2016; accepted for publication June 27, 2016; available ahead of print July 27, 2016.

Address for reprints: Wilson Y. Szeto, MD, Division of Cardiovascular Surgery, Penn Presbyterian Medical Center, University of Pennsylvania, 51 N 39th St, Heart and Vascular Pavilion 2A, Philadelphia, PA 19104 (E-mail: Wilson.szeto@uphs.upenn.edu).

J Thorac Cardiovasc Surg 2016;152:1319-20

$0022-5223 / \$ 36.00$

Copyright (C) 2016 by The American Association for Thoracic Surgery

http://dx.doi.org/10.1016/j.jtcvs.2016.07.008
}

The Streamliner Multilayer Flow Modulator (SMFM; Cardiatis, Isnes, Brussels, Belgium) is composed of several layers of cobalt braided alloy and is designed to treat aneurysm pathology by reducing arterial wall tension while simultaneously preserving flow into branch vessels. This technology marks a paradigm shift in the treatment of aortic aneurysms. The device promotes laminar flow, with more reliance on the natural healing capabilities of the vascular endothelium. CE Mark approval for aortic procedures was granted in July 2011, and a recent meta-analysis reported a 1-year aneurysm-related survival of nearly $80 \%$ in 171 patients combined from 15 studies. ${ }^{1}$

In their article in this issue of the Journal, Stefanov and coauthors $^{2}$ report their study of hemodynamic computational data derived from the treatment of complex aortic arch aneurysm with the SMFM. Among their total of 6 patients, 4 with pure arch pathology and 2 with type I thoracoabdominal aneurysm, their computational analysis revealed favorable blood flow patterns within the sac regions and reduction of sac volume in 4 patients at 1-year follow-up. Side branch vessel patency was also favorable in all patients. Stefanov and coauthors ${ }^{2}$ conclude that SMFM with advanced imaging and computational analysis may offer a new technologic advance in the endovascular therapy of complex arch pathologies.

The treatment for aortic arch pathology has historically consisted of open techniques requiring total arch replacement with period of circulatory arrest. Even in high-risk patient populations, acceptable results can be achieved, and this open surgical approach remains the criterion standard at many centers. ${ }^{3,4}$ The rapid expansion of thoracic endovascular technology in the past 15 years, however, is expanding the armamentarium for surgeons who manage complex aortic pathologies. With ongoing evolution in this arena, it is imperative to reassess

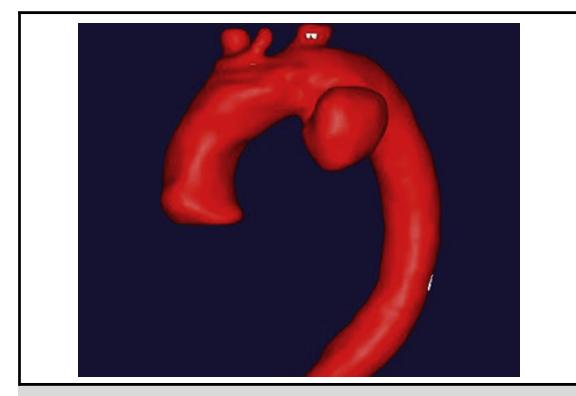

Large saccular aortic arch aneurysm emanating from the lateral aspect of the aortic arch.

\section{Central Message}

The Streamliner multilayer flow modulator offers a potential technologic advance in the treatment of complex aortic arch and thoracoabdominal aortic pathology.

See Article page 1309.

critically the current status of surgical options for treating aortic arch pathologies (Figure 1). It is also incumbent on cardiovascular surgeons to embrace innovation and provide constructive input as the device industry works to develop disease-specific endovascular devices.

In their study, Stefanov and coauthors ${ }^{2}$ performed a technically rigorous computational analysis, which provided

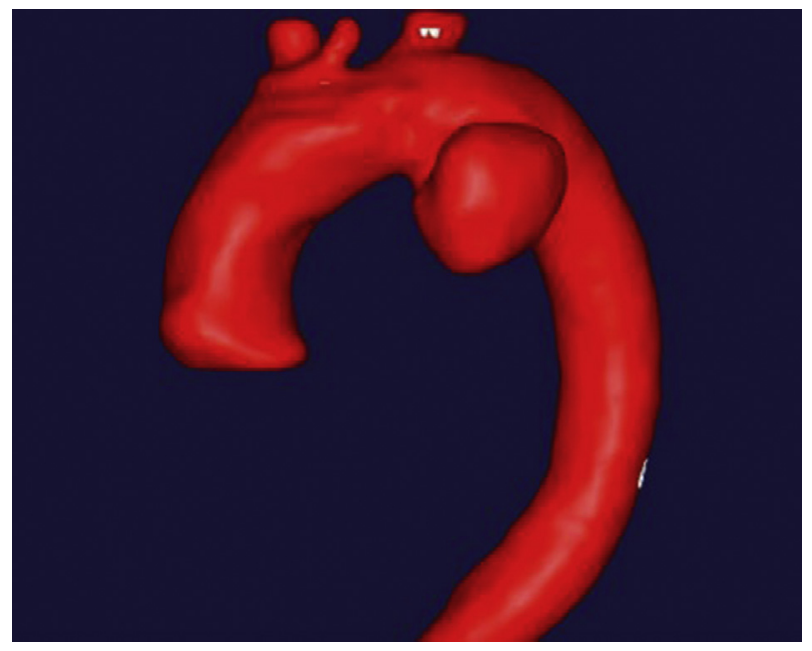

FIGURE 1. Large saccular aortic arch aneurysm emanating from the lateral aspect of the aortic arch. 
several important insights that warrant emphasis. They observed improved flow dynamics when devices were deployed under the instructions for use. In patients with treatment outside the instructions for use, mainly as a result of stent foreshortening during positioning, less favorable flow dynamics were observed. Furthermore, in those patients with treatment outside the instructions for use, aneurysm volume expansion of nearly $25 \%$ was seen. One of the patients treated for a thoracoabdominal aortic aneurysm had an extensive aneurysm length, generating a large volume of flow, which could not be modulated by the SMFM devices. This observation led Stefanov and coauthors $^{2}$ to conclude that the SMFM device does not offer benefit if the sac volume exceeds $400 \mathrm{~cm}^{3}$.

The SMFM technology represents a novel approach to the treatment of complex aortic pathology. Although this study was limited to a very small sample of patients, it does provide important insights into a potentially transformative technologic advancement in device design for thoracic endovascular aortic repair. More clinical outcome data are needed before definitive commentary can be made regarding the effectiveness and long term durability of this technology. Stefanov and coauthors ${ }^{2}$ should be commended for their significant contribution to this field.

\section{References}

1. Hynes N, Sultan S, Elhelali A, Diethrich EB, Kavanagh EP, Sultan M, et al. Systematic review and patient-level meta-analysis of the streamliner multilayer flow modulator in the management of complex thoracoabdominal aortic pathology. J Endovasc Ther. 2016;23:501-12.

2. Stefanov F, Morris L, Elhelali A, Kavanagh EP, Lundon V, Hynes N, et al. Insights from complex aortic surgery with a Streamliner device for aortic arch repair (STAR). J Thorac Cardiovasc Surg. 2016;152:1309-18.e5.

3. Preventza O, Garcia A, Cooley DA, Haywood-Watson RJ, Simpson K, Bakaeen FG, et al. Total aortic arch replacement: a comparative study of zone 0 hybrid arch exclusion versus traditional open repair. $J$ Thorac Cardiovasc Surg. 2015;150:1591-8; discussion 1598-600.

4. Iafrancesco M, Ranasinghe AM, Dronavalli V, Adam DJ, Claridge MW, Riley P, et al. Open aortic arch replacement in high-risk patients: the gold standard. Eur J Cardiothorac Surg. 2016;49:646-51; discussion 651. 